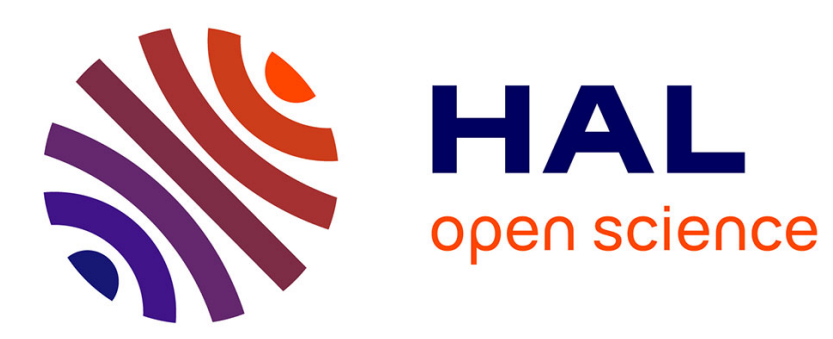

\title{
Computer Simulations Provide Guidance for Molecular Medicine through Insights on Dynamics and Mechanisms at the Atomic Scale
}

\author{
Marc Baaden
}

\section{- To cite this version:}

Marc Baaden. Computer Simulations Provide Guidance for Molecular Medicine through Insights on Dynamics and Mechanisms at the Atomic Scale. In: Van Toi V., Le T., Ngo H., Nguyen TH. (eds). 7th International Conference on the Development of Biomedical Engineering in Vietnam (BME7) Translational Health Science and Technology for Developing Countries, 69, Springer, pp.261-265, 2020, IFMBE Proceedings, 10.1007/978-981-13-5859-3_47 . hal-02370021

\section{HAL Id: hal-02370021 \\ https://hal.science/hal-02370021}

Submitted on 19 Nov 2019

HAL is a multi-disciplinary open access archive for the deposit and dissemination of scientific research documents, whether they are published or not. The documents may come from teaching and research institutions in France or abroad, or from public or private research centers.
L'archive ouverte pluridisciplinaire HAL, est destinée au dépôt et à la diffusion de documents scientifiques de niveau recherche, publiés ou non, émanant des établissements d'enseignement et de recherche français ou étrangers, des laboratoires publics ou privés. 


\title{
Computer Simulations Provide Guidance for Molecular Medicine through Insights on Dynamics and Mechanisms at the Atomic Scale
}

\author{
Marc Baaden ${ }^{[0000-0001-6472-0486]}$ \\ Laboratoire de Biochimie Théorique, CNRS, UPR9080, Univ Paris Diderot, \\ Sorbonne Paris Cité, PSL Research University, 13 rue Pierre et Marie Curie, 75005, Paris, \\ France \\ baaden@smplinux.de
}

\begin{abstract}
Computer simulations provide crucial insights and rationales for the design of molecular approaches in medicine. Several case studies illustrate how molecular model building and molecular dynamics simulations of complex molecular assemblies such as membrane proteins help in that process. Important aspects relate to build relevant molecular models with and without a crystal structure, to model membrane aggregates, then to link (dynamic) models to function, and finally to understand key disease-triggering phenomena such as aggregation. Through selected examples - including key signaling pathways in neurotransmission - the links between a molecular-level understanding of biological mechanisms and original approaches to treat disease conditions will be illuminated. Such treatments may be symptomatic, e.g. by better understanding the function and pharmacology of macromolecular key players, or curative, e.g. through molecular inhibition of disease-inducing molecular processes.
\end{abstract}

Keywords: Molecular dynamics, Model building, Molecular mechanisms of disease.

\section{Introduction}

Models at the molecular level play a crucial role for the field of medicine, or more generally-speaking biology. Their importance goes back well before the use of computational approaches: for instance Watson and Crick used a mechanical model fabricated in a workshop to gain insight into DNA structure. Such modeling approaches are nowadays carried out on the computer, be it with a laptop or at a supercomputer centre. They are very useful, from trying to understand the key properties of molecular building blocks such as metabolites, sugars, lipids and macromolecular fragments to rationalizing the effect of mutations, identifying specific regions of interest, for instance aggregation-prone ones, characterizing the dynamics of biological and medical processes, and to gain insight into fundamendal mechanisms governing disease.

Beyond such qualitative observations, the quantitative implementation of the modeling process in relation to verifyable experimental measures represents one of the 
key challenges. There are a few direct points of comparison, for example distances in a model can be linked to FRET experiments, which are of interest for the validation of the models, but not for medical purposes. Free energies and binding affinities may provide quantitative information on the effect of mutations or the potency of drug molecules, yet a direct prediction leading from the molecular level to a measurable impact on disease conditions is nowadays clearly out of scope. Such a goal would at the very least require to anticipate the complex interrelationships in metabolic networks - where the actors examined by molecular modeling are interconnected through a web of other macromolecules - by linking the molecular level with a systems biology representation. An overall scheme is provided in Figure 1.

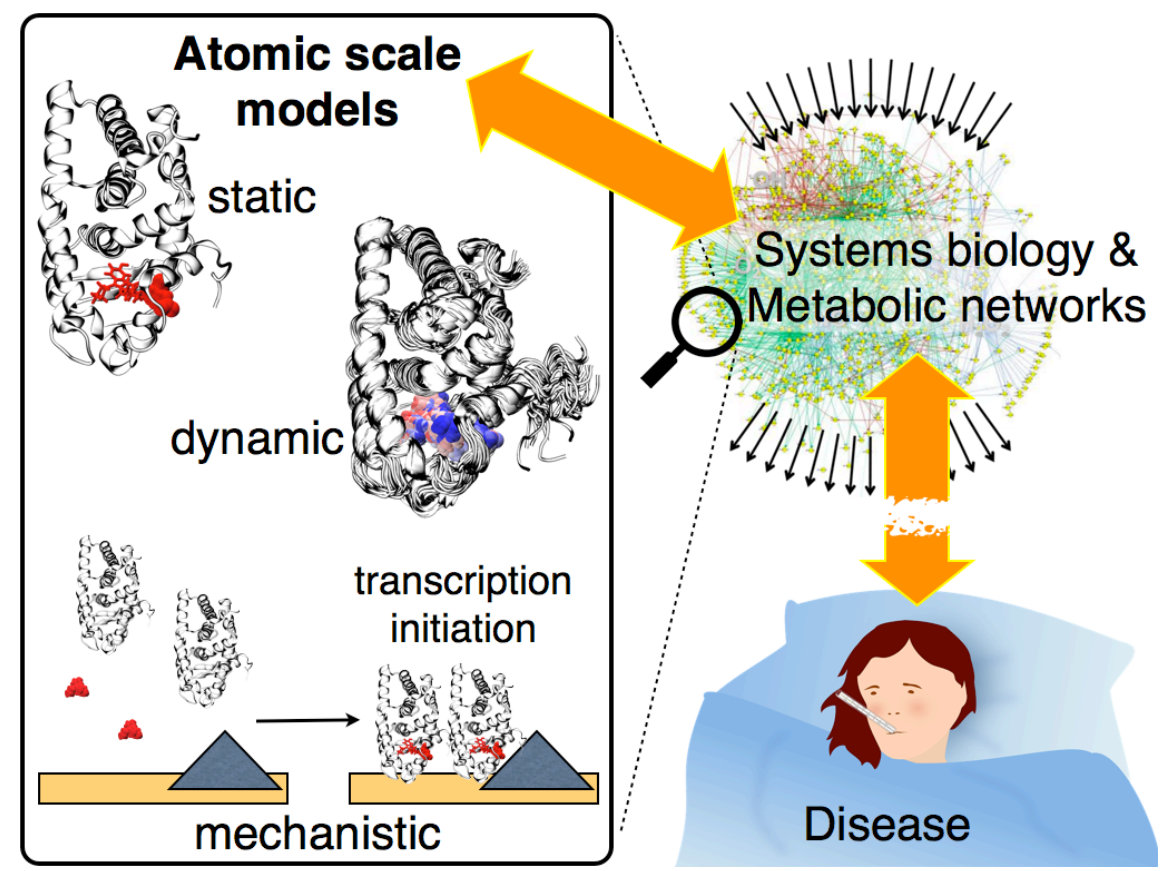

Figure 1. Schematic view of the connections between atomic scale models, representing a zoom of complex interrelated metabolic networks, and disease, as a consequence of a network perturbation. Atomic scale models are illustrated with the estrogen receptor based on simulations described in [1], showing a static model with a key mutation and a drug molecule highlighted in red. A dynamic picture is provided as the next level of interpretation, here drug and mutation are colored from blue to red as a function of timestep. Then, these computational models need to fit into a mechanistic picture, here of estrogen receptor assembly, initiated by an estrogen signal and leading to the initiation of transcription.

In this contribution, we focus on the atomic scale aspects using several case studies. It is illustrated how computational approaches, in particular molecular model building and molecular dynamics simulations of complex molecular assemblies such as membrane proteins help in understanding these molecular processes. The examples 
comprise important aspects related to building medically relevant molecular models with and without a crystal structure, to model aggregates, then to link (dynamic) models to function, and finally to understand key disease-triggering phenomena such as aggregation. In each case, the links between a molecular-level understanding of biological mechanisms and original approaches to treat disease conditions will be briefly illuminated. Such treatments may be symptomatic through a better understanding of the function and pharmacology of macromolecular key players, or curative, through molecular inhibition of disease-inducing molecular processes, for instance. The manuscript ends with an overview of upcoming new tools that are likely to further improve the power of computational approaches in the near future.

\section{$2 \quad$ Linking computer simulations to disease}

The key challenge for computer simulations to be of relevance for molecular medicine is to establish a clear link between the insight gained at the atomic scale and a given disease. This aspect is explored from three directions, $i$ ) the value of static, three-dimensional molecular models, ii) adding dynamic information to such models, and iii) considering the bigger picture of molecular mechanisms underpinning disease. All modeling studies rely on a set of methods and tools to run, inspect and interpret them. We conclude with a perspective on current trends to improve and extend the portfolio of tools, with the potential to provide important breakthroughs in the future.

\subsection{Learning from molecular models}

How to build molecular models. In the simplest case, a disease may be directly linked to a specific single-point mutation of a key molecule, the understanding of which may provide important clues for therapies. Hence, building a 3-dimensional allatom model is a fundamental step on the way to better treatment. When the crystal or NMR structure of the key molecule is known, model building follows a standard procedure. Typical approaches and setups are described in [2,3], highlighting specific issues that may arise with membrane proteins. In a typical setup, it is required to choose among potential alternative conformations, correct for mutations that may have been required to achieve crystallization, and possibly predict the protonation states of ionizable amino acids including His, Asp, Glu, Arg and Lys residues. A relation to diseases may be established by analyzing the 3D positions of mutations and their molecular environment. This is the case for the low density lipoprotein receptor [4], contributing to cholesterol cleansing in the blood. We analyzed four point mutation sites involved in familiar hypercholesterolemia, the main risk factor in atherosclerosis, and understood their molecular origin through visual inspection revealing an influence of nearby calcium ions, disulfide bridges, electrostatic and steric effects as illustrated in Figure 2. 


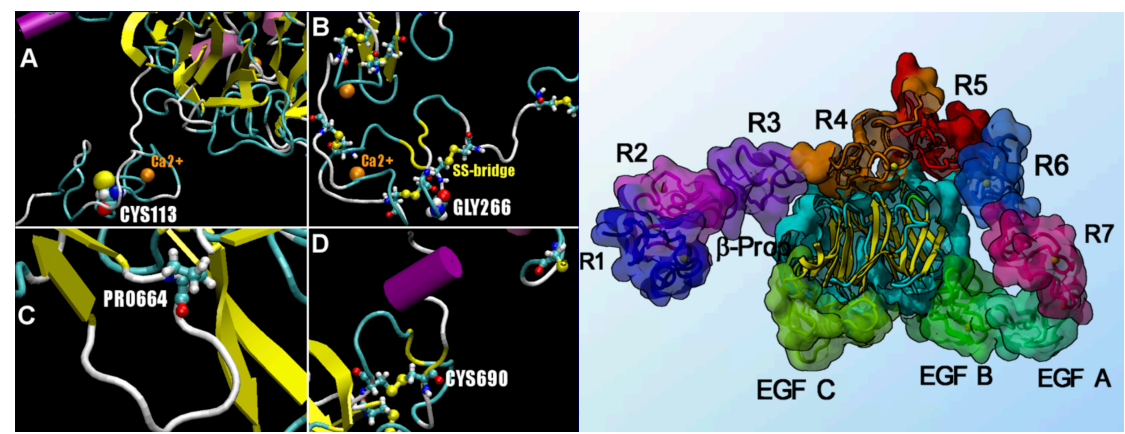

Figure 2. Closeup of the low density lipoprotein receptor (LDLR) mutation sites and nearby points of interest are shown on the left panel and labelled A to D. The right panel shows the extracellular domain of LDLR at $\mathrm{pH} 5$ where these mutations are located.

The effects of the four point mutations we studied were interpreted as follows. C113R is involved in a stabilizing disulfide bridge (Fig. 2A) which will be lost upon mutation. The positively charged Arg-mutant will furthermore repel the nearby calcium ion. The G266C residue shown in Fig. 2B sits between two close and several more distant disulfide bridges. The cysteine mutant might lead to the formation of alternative disulfide bridges. Its negative charge might lead to a change in coordination of the nearby calcium. P664L is in contact with a beta-sheet and part of a loop (Fig. 2C). The Leu mutant is bulkier and no kink is induced. C690S is involved in a disulfide bridge (Fig. 2D) which seems essential to maintain the local geometry.

Modeling without a crystal structure. The most common case is that the precise structure of the molecule of interest is unknown. In the absence of any structurally exploitable data (e.g. indirect experimental measurements), homology modeling is a common choice. We employed such an approach to model a full-length Fzol mitofusin, involved in membrane fusion, a fundamental mechanism which remains unclear [5]. Mutations in the related human mitofusin MFN2 cause Charcot-MarieTooth disease type 2a [6], which is characterized by degeneration of long peripheral nerves. Furthermore, mitofusins can be linked to the etiology of Parkinson disease [7]. The predicted architecture of our model improves upon the current domain annotation, with a precise description of the helical spans linked by exible hinges, and provided indications for several interesting mutations that were carried out and tested experimentally.

A slightly different situation is observed when experimental data is available to guide the modeling process. For example, the molecular knowledge of dystrophin, a protein mutated in myopathy patients, remains limited, yet it is amenable to Smallangle X-ray Scattering (SAXS) investigations. We designed an original interactive docking method to model full-length dystrophin based on its fragments, integrating qualitative experimental data restraints [8]. This model allowed us to show that the central dystrophin domain is a tortuous and complex filament, profoundly disorganized by the most severe Becker muscular dystrophy deletions. The structural descrip- 
tion gained through our model represents a first necessary step to improve the design of microdystrophin constructs in the goal of a successful gene therapy for the severe Duchenne muscular dystrophy [9].

\subsection{Adding dynamics and linking to function}

So far, we mostly considered static three-dimensional models, yet, dynamics is a key factor in biological systems and processes. Typical simulation setups are described in the literature $[10,3]$. An interesting and straightforward application example are pharmacological chaperones (PC) used for the treatment of Fabry disease [11,12]. Fabry disease is a rare pathology caused by mutations of lysosomal alphagalactosidase. About $40 \%$ of all the disease missense mutations occur at flexible sites of the protein [13], destabilizing it and leading to clearance by the quality control system of the cell. An oral PC therapy uses 1-deoxygalactonojirimycin that reversibly binds to the active site of the enzyme and stabilizes it. We demonstrated the effectiveness of molecular dynamics (MD) simulations to correlate the genotype to the severity of the disease. More generally, destabilizing mutations are widely encountered in other proteins, hence MD may be useful for diagnostic purposes in other human diseases.

\subsection{Moving towards mechanisms}

Previous examples focused on simple relationships between molecular models, static or dynamic, and disease conditions. For many diseases the situation is more intricate, requiring to understand entire complex molecular mechanisms leading to disease. The modeling task may involve multi-step molecular processes with several actors in complex environments such as the membrane. General anesthesia $(\mathrm{GA})$ is such an example. Although GA is not a disease, a better understanding of its mechanism is of medical relevance as it would enable us to design better compounds and more efficient palliative treatments. The mechanism of action remains a matter of controversy. One proposed mode of action involves binding of anesthetic molecules to ligand gated ion channels, modulating their function. We explored this mode at the molecular level by studying the membrane-inserted pentameric ligand-gated ion channel GLIC for which many anesthetic binding sites were characterized. By performing MD simulations to gain key insights on binding location and affinity, in particular microsecond-long flooding simulations, combined with free energy calculations, we characterized access to binding sites and quantified binding affinities. This study revealed a complex network of interconnected binding sites, possibly all contributing in concert to the anesthetic effect [14].

Another fundamendal mechanism of medical importance is aggregation, leading to proteinopathies and neurodegenerative disorders. Modeling approaches have been widely used to study Alzheimer's, as reviewed in $[15,16]$. In particular multi-scale and multi-physics simulations may be required to address the sampling and time-scale challenges imposed by the underlying processes [17], with some involved molecules being possibly intrinsically disordered. 


\subsection{Towards new and improved tools}

All studies described in this article require adequate modeling tools. Continuous improvement of algorithms, hardware and technology lead to new approaches to be explored. Key trends and upcoming new tools in computational biology may involve for instance interactive model building and simulation as a very promising approach, in particular when the methods are rendered robust enough such that non-specialists can use them. In the current era of integrative modeling, much is yet to come in terms of combining experimental data with modeling approaches. Another development is next-level computational power, increasingly exploited through GPU computing, and soon to be boosted by exa-scale high performance computing. These developments lead to a much increased amount of data to interpret, and hence advanced analysis tools are the next big challenge. Interactive approaches such as visual analytics help the rationalization process, deep learning approaches may uncover complex relationships in the data. Closely related are advanced visualization techniques, in particular immersive ones such as virtual reality and augmented reality. They allow us to scrutinize complex three-dimensional datasets in a natural and intuitive way.

\section{Conclusion}

Computational modeling approaches bear great promise for understanding disease conditions and to design improved and novel therapies. A few examples on how to establish a link between the atomistic modeling scale and the medical implications were discussed. Two strategies for treatments can be envisaged. In the symptomatic approach, a better understanding of the function and pharmacology of macromolecular key players is targeted. For curative approaches, a deeper understanding of disease-inducing molecular processes is required such that e.g. molecular inhibitors for critical steps can be designed. With the current developments in terms of computational power, intuitive, immersive and interactive analysis and manipulation methods, much progress is yet to be expected in the near future.

\section{Acknowledgments}

This work was supported by the Fondation pour la Recherche Médicale, grant number FRM DBI20141231801, the Air Liquide, Servier and UCB Biopharma companies, and the "Initiative d'Excellence" program from the French State (Grants "DYNAMO", ANR-11-LABX-0011-01 and ANR-11-EQPX-0008).

\section{Conflict of Interest}

The author declares that he has no conflict of interest. 


\section{References}

1. Sinha, D.K., Neveu, P., Gagey, N., Aujard, I., Benbrahim-Bouzidi, C., Le Saux, T., Rampon, C., Gauron, C., Goetz, B., Dubruille, S., Baaden, M., Volovitch, M., Bensimon, D., Vriz, S., Jullien, L.: Photocontrol of protein activity in cultured cells and zebrafish with one- and two-photon illumination. Chembiochem 11(5), 653-663 (2010). doi:10.1002/cbic.201000008

2. Hénin, J., Baaden, M., Taly, A.: Foundations of Biomolecular Simulations: A Critical Introduction to Homology Modeling, Molecular Dynamics Simulations, and Free Energy Calculations of Membrane Proteins. In: Membrane Proteins Production for Structural Analysis. Springer, New York, NY (2014)

3. Murail, S.: Simulation of Ligand Binding to Membrane Proteins. In: Membrane Protein Structure and Function Characterization, vol. 1635. Methods in Molecular Biology, pp. 359-381. Humana Press, New York, NY (2017)

4. El Messal, M., Ait Chihab, K., Chater, R., Vallve, J.C., Bennis, F., Hafidi, A., Ribalta, J., Varret, M., Loutfi, M., Rabes, J.P., Kettani, A., Boileau, C., Masana, L., Adlouni, A.: Familial hypercholesterolemia in Morocco: first report of mutations in the LDL receptor gene. J Hum Genet 48(4), 199-203 (2003). doi:10.1007/s10038-003-0010-x

5. De Vecchis, D., Cavellini, L., Baaden, M., Henin, J., Cohen, M.M., Taly, A.: A membrane-inserted structural model of the yeast mitofusin Fzo1. Sci Rep 7(1), 10217 (2017). doi:10.1038/s41598-017-10687-2

6. Zuchner, S., Mersiyanova, I.V., Muglia, M., Bissar-Tadmouri, N., Rochelle, J., Dadali, E.L., Zappia, M., Nelis, E., Patitucci, A., Senderek, J., Parman, Y., Evgrafov, O., Jonghe, P.D., Takahashi, Y., Tsuji, S., Pericak-Vance, M.A., Quattrone, A., Battaloglu, E., Polyakov, A.V., Timmerman, V., Schroder, J.M., Vance, J.M.: Mutations in the mitochondrial GTPase mitofusin 2 cause Charcot-Marie-Tooth neuropathy type 2A. Nat Genet 36(5), 449-451 (2004). doi:10.1038/ng1341

7. Chen, Y., Dorn, G.W., 2nd: PINK1-phosphorylated mitofusin 2 is a Parkin receptor for culling damaged mitochondria. Science 340(6131), 471-475 (2013). doi: $10.1126 /$ science. 1231031

8. Molza, A.E., Ferey, N., Czjzek, M., Le Rumeur, E., Hubert, J.F., Tek, A., Laurent, B., Baaden, M., Delalande, O.: Innovative interactive flexible docking method for multi-scale reconstruction elucidates dystrophin molecular assembly. Faraday Discuss 169, 45-62 (2014). doi:10.1039/c3fd00134b

9. Delalande, O., Molza, A.E., Dos Santos-Morais, R., Cheron, A., Pollet, E., Raguenes-Nicol, C., Tascon, C., Giudice, E., Guilbaud, M., Nicolas, A., Bondon, A., Leturcq, F., Ferey, N., Baaden, M., Perez, J., Roblin, P., PietriRouxel, F., Hubert, J.F., Czjzek, M., Le Rumeur, E.: Dystrophin's central domain forms a complex filament that becomes disorganized by in-frame deletions. J Biol Chem (2018). doi:10.1074/jbc.M117.809798 
10. Laurent, B., Murail, S., Da Silva, F., Corringer, P.-J., Baaden, M.: Modeling complex biological systems: From solution chemistry to membranes and channels. Pure and Applied Chemistry 85(1) (2013).

11. Germain, D.P., Hughes, D.A., Nicholls, K., Bichet, D.G., Giugliani, R., Wilcox, W.R., Feliciani, C., Shankar, S.P., Ezgu, F., Amartino, H., Bratkovic, D., Feldt-Rasmussen, U., Nedd, K., Sharaf El Din, U., Lourenco, C.M., Banikazemi, M., Charrow, J., Dasouki, M., Finegold, D., Giraldo, P., GokerAlpan, O., Longo, N., Scott, C.R., Torra, R., Tuffaha, A., Jovanovic, A., Waldek, S., Packman, S., Ludington, E., Viereck, C., Kirk, J., Yu, J., Benjamin, E.R., Johnson, F., Lockhart, D.J., Skuban, N., Castelli, J., Barth, J., Barlow, C., Schiffmann, R.: Treatment of Fabry's Disease with the Pharmacologic Chaperone Migalastat. N Engl J Med 375(6), 545-555 (2016). doi:10.1056/NEJMoa1510198

12. Hughes, D.A., Nicholls, K., Shankar, S.P., Sunder-Plassmann, G., Koeller, D., Nedd, K., Vockley, G., Hamazaki, T., Lachmann, R., Ohashi, T., Olivotto, I., Sakai, N., Deegan, P., Dimmock, D., Eyskens, F., Germain, D.P., GokerAlpan, O., Hachulla, E., Jovanovic, A., Lourenco, C.M., Narita, I., Thomas, M., Wilcox, W.R., Bichet, D.G., Schiffmann, R., Ludington, E., Viereck, C., Kirk, J., Yu, J., Johnson, F., Boudes, P., Benjamin, E.R., Lockhart, D.J., Barlow, C., Skuban, N., Castelli, J.P., Barth, J., Feldt-Rasmussen, U.: Oral pharmacological chaperone migalastat compared with enzyme replacement therapy in Fabry disease: 18-month results from the randomised phase III ATTRACT study. J Med Genet 54(4), 288-296 (2017). doi:10.1136/jmedgenet-2016-104178

13. Cubellis, M.V., Baaden, M., Andreotti, G.: Taming molecular flexibility to tackle rare diseases. Biochimie 113, 54-58 (2015). doi:10.1016/j.biochi.2015.03.018

14. Laurent, B., Murail, S., Shahsavar, A., Sauguet, L., Delarue, M., Baaden, M.: Sites of Anesthetic Inhibitory Action on a Cationic Ligand-Gated Ion Channel. Structure 24(4), 595-605 (2016). doi:10.1016/j.str.2016.02.014

15. Nguyen, P., Derreumaux, P.: Understanding amyloid fibril nucleation and abeta oligomer/drug interactions from computer simulations. Acc Chem Res 47(2), 603-611 (2014). doi:10.1021/ar4002075

16. Nasica-Labouze, J., Nguyen, P.H., Sterpone, F., Berthoumieu, O., Buchete, N.V., Cote, S., De Simone, A., Doig, A.J., Faller, P., Garcia, A., Laio, A., Li, M.S., Melchionna, S., Mousseau, N., Mu, Y., Paravastu, A., Pasquali, S., Rosenman, D.J., Strodel, B., Tarus, B., Viles, J.H., Zhang, T., Wang, C., Derreumaux, P.: Amyloid beta Protein and Alzheimer's Disease: When Computer Simulations Complement Experimental Studies. Chem Rev 115(9), 3518-3563 (2015). doi:10.1021/cr500638n

17. Sterpone, F., Doutreligne, S., Tran, T.T., Melchionna, S., Baaden, M., Nguyen, P.H., Derreumaux, P.: Multi-scale simulations of biological systems using the OPEP coarse-grained model. Biochem Biophys Res Commun 498(2), 296-304 (2018). doi:10.1016/j.bbrc.2017.08.165 